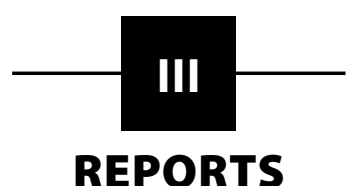

\title{
After the Return
}

\section{Digital Repatriation and the Circulation of Indigenous Knowledge Workshop Report}

\author{
Joshua A. Bell, Kimberly Christen, and Mark Turin
}

ABSTRACT: On 19 January 2012, the workshop After the Return: Digital Repatriation and the Circulation of Indigenous Knowledge was held at the Smithsonian Institution's National Museum of Natural History in Washington DC. With support from the National Science Foundation and the Smithsonian's Understanding the American Experience and Valuing World Cultures Consortia, this workshop brought together twenty-eight international participants for a debate around what happens to digital materials after they are returned to communities (however such communities are conceived, bounded, and lived). The workshop provided a unique opportunity for a critical debate about the very idea of digital return in all of its problematic manifestations, from the linguistic to the legal, as indigenous communities, archives, libraries, and museums work through the terrain of digital collaboration, return, and sharing. What follows is a report on the workshop's presentations and discussions.

KEYWORDS: access, collaboration, circulation, collections, digital return, knowledge, museums

On 19 January 2012, we, the authors, convened a workshop entitled After the Return: Digital Repatriation and the Circulation of Indigenous Knowledge at the Smithsonian Institution's National Museum of Natural History $(\mathrm{NMNH})$ in Washington DC. ${ }^{1}$ With support from the National Science Foundation (Grant No. 7115841) and the Smithsonian's Understanding the American Experience and Valuing World Cultures Consortia, this workshop brought together twenty-eight participants for two and half days of sustained and open debate around what happens to digital materials after they are returned to communities (however such communities are conceived, bounded, and lived).

This workshop emerged from ongoing discussions and from lessons learned from our respective fieldwork, interactions in and around museums, and digital explorations. As we explored in the workshop, it is clear that giving and receiving are rarely monodirectional or linear, and have to be thought of as reciprocal and cyclical ongoing processes (Bell 2008, 2010; Christen 2005, 
2009; Turin 2007, 2011). Indigenous communities, museums, archives, and libraries, as well as individuals and family groups, are increasingly using digital materials in sophisticated and intersecting ways (e.g., Boast et al. 2007; Geismar and Mohns 2011; Salmond 2012). This use productively builds on and is in dialogue with the complex ways communities have been and continue to use visual media to assert their sovereignty, challenge the terms and nature of representation, and create new intercultural dynamics (cf. Ginsburg et al. 2002). At the same time, the institutions and scholars engaged in processes of return and 'repatriation'-whether these are digital or analog objects-continue to grapple with ever more complex notions of circulation and the ethical dilemmas and institutional barriers with which they were associated (e.g., Peers and Brown 2003; Coombe 2009; Philips 2012).

Critically engaging with these issues, the Digital Return workshop was thus born out of our collective desire to initiate a wider discussion with a diverse group of practitioners and community members who had been engaged in similar projects for many years. The workshop provided a unique opportunity to nurture further interaction, and to facilitate critical debate about the very idea of digital return in all of its problematic manifestations, from the linguistic to the legal. Digital repatriation can be a contentious term that generates reflex assumptions about the relationship between digital and material forms of cultural heritage materials. While it may be tempting to assume, at first glance, that the digital object-as a surrogate-somehow replaces the physical object, no standard definition, nor agreed-upon terminology, characterizes the multiple practices of collecting institutions, individuals, or local community groups surrounding the return of cultural and historical materials to indigenous communities in a digital form (Cameron and Kenderdine 2007). Digital surrogates are not always intended to replace, or be synonymous with, the physical materials that they may represent. Instead, digital (or digitized) cultural materials may also provide an alternative form of-and dynamic life for-certain physical objects. Such newly digitized and repatriated materials may be the impetus for linguistic or cultural revival, spur contention and disagreement, prompt new cultural forms or popular products, incite new collaborations, and engender new types of performances and artistic creations.

One of the most promising and dynamic sites for anthropological collaboration with indigenous communities has been in the field and practice of digital repatriation. Over the last twenty years, collecting institutions-museums, libraries, archives, and individual scholars-have heeded calls by indigenous peoples to integrate indigenous curatorial models and understandings into mainstream museum and archive practices, from cataloguing to display modes (e.g., Karp et al. 2006; Crowell et al. 2010; Christen 2011). With the growth of new digital technologies, anthropologists, museum professionals, and indigenous communities have collaborated to produce new models for the creation, circulation, and reproduction of knowledge and cultural materials. The more recent development of Web 2.0 technologies grounded in user-generated content and bottom-up exhibition and display techniques has produced a dynamic platform for sharing materials. Web-based photo-sharing platforms such as Flickr and, more recently, online publishing tools like Omeka allow people to take advantage of low-cost or no-cost technologies to create exhibits and circulate physical objects in their digital form. ${ }^{2}$

This newly animated digital terrain poses both possibilities and problems for indigenous peoples as they seek to manage, revive, circulate, and create new cultural heritage materials. While digital technologies allow for materials to be repatriated quickly, circulated widely, and annotated endlessly, these same technologies pose challenges to indigenous communities who wish to maintain traditional cultural protocols for the viewing, circulation, and reproduction of these new cultural materials. Many indigenous communities wish to maintain control over the circulation of certain types of knowledge and cultural materials based on their own cultural systems (Christen 2009). Digital technologies and the Internet have combined to produce both the 
possibility for greater indigenous access to material collections held in collecting institutions, as well as a new set of tensions for communities who wish to control these materials and thereby limit their access and circulation. Although many museums, archives, and libraries have been quick to acknowledge indigenous knowledge models and provide digital surrogates for communities who request them, these institutions have not attempted to systematically track how or if these materials have subsequently been used, reused, altered, and reframed.

Until now, most of the research on digital repatriation has focused on the act of giving back; less attention has been paid to how these materials are circulated and accessed once they are 'home'; that is, what happens once digital materials are returned? This set of questions leads to others: How are these materials controlled and circulated within the community? Do they serve different purposes for local communities and other interested parties? How does the mode of access - an institutional online catalogue versus an indigenous Web portal-impact the practices of knowledge creation or revitalization? How are these newly formed cultural materials used within local social and cultural systems? Can digitally repatriated objects facilitate new knowledge creation and the revitalization of endangered languages and cultural practices simultaneously? If so, how are they mobilized within these projects? Can these projects inform international debates concerning indigenous traditional knowledge protection and the promotion of indigenous intellectual property rights? These are just some of the contentious questions that the participants of our workshop sought to address.

\section{"If the digital is so good, why don't you keep it?"}

We were privileged to have Jim Enote, the director of the A:shiwi A:wan Museum and Heritage Center at Zuni in North America, as the keynote speaker at the workshop. ${ }^{3}$ Moving deftly from a narrative reflecting on his grandmother's humility about her global connections as an artist to the necessity of tribal control and ownership of cultural materials, Enote's keynote emphasized the generative possibilities of new media alongside the necessity of tribal involvement from the ground up. Despite his enthusiasm for the workshop, he was pointedly critical of the idea of digital repatriation, and noticeably more comfortable with the more neutral terminology of return. If digital surrogates were so good, Enote reasoned, why didn't the institutions, researchers, and scholars keep them, and return the original, nondigitized, analog object to the community instead?

Enote's welcome provocation about aspects of repatriation-what the process truly constitutes-and the responsibilities of giving and circulating knowledge stayed with us throughout our two and half days of discussions, and served as powerful inspiration for many of the presentations that followed. His address reinforced why we had organized the workshop with the notion of 'return' specifically to signal it as an umbrella under which many different forms of practicesrepatriation being just one-could be clustered, each of which had specific impacts and value for different contexts. Enote's keynote address served to remind us that there are many types of return, and they are all always already embedded in the relationships and histories of the past and at the same time point to possibilities for the future. His desire to push us past the notion of repatriation as the return of digital copies underscores the need to unpack all the circulation routes of digital materials-as they become digital and move into multiple spheres of interaction.

The workshop was organized along four overlapping thematic lines, each of which was broken up by shorter presentations that focused on how the work undertaken at the Smithsonian Institution was reconnecting indigenous communities with cultural and linguistic materials through both physical and digital repatriation and return projects. The first day of the work- 
shop focused on the first two themes, and the second day of the workshop focused on the other two themes.

1. Collaborations and communications highlighted the issue of forging the partnerships-faceto-face as well as with and through technology — that are needed to facilitate the return of cultural and linguistic materials. Collaborators addressed the challenges and successes of their joint projects and relationships. Panelists Guha Shankar (American Folklife Center, Library of Congress) and Cordelia Hooee (Librarian, Zuni Public Library); Kate Hennessy (Simon Fraser University), Mervin Joe (Inuvialuit Living History project team), and Stephen Loring (Smithsonian); and Peter Brand (Director, First Voices) and Victoria Wells (Ehattesaht community member and language activist) spoke frankly about what it takes to form and sustain such relationships, as well as what factors can impede long-lasting partnerships.

Shankar and Hooee (in absentia) presented their respective perspectives from their institutions in relation to the return of the Doris Duke Zuni Storytelling collection. They dwelled upon the necessity of tribal involvement in the process of return, but highlighted the many institutional and tribal roadblocks that can lie in the way of such projects. In particular, they emphasized the need for open channels of communication and multilevel approaches to digital return projects. Hennessey, Joe (who joined us via Skype due to a snow storm), and Loring elaborated on their collaboration to research and document the Smithsonian's MacFarlane Collection as part of the Inuvialuit Living History project (http://www.inuvialuitlivinghistory.ca/). Emerging out of the Reciprocal Research Network (RRN), the group is creating a digital 'living archive' to explore the divergent but ultimately connected histories that these materials contain and give rise to. A key aspect of the project's methodology is the way that it explicitly involves members of different generations to facilitate the construction of the digital collections and support the flow of knowledge among the project team. For their contribution, Brand and Wells discussed their working partnership using the First Voices language tool suite. With practical advice and examples of technological necessities and cultural needs, they showcased how tribal involvement leads to flourishing language programs on the ground in First Nations communities. They also demonstrated how trust, respect, and mutual recognition lie at the heart of this project, and indeed have to permeate all effective digital collaborations. For Wells, who hails from the Ehattesaht community in Canada, the terms repatriation and return were to be encouraged, as both the words themselves and the practices that they refer to convey and entail respect. She saw the political act of return as connecting to types of repatriation she had observed in her community and other First Nations aboriginal communities. All of these collaborations have been forged at the crossroads of digital technologies, national and local repatriation movements, the desire for cultural and linguistic revitalization, and the ongoing creation of culture and cultural practices within indigenous communities.

This panel was followed by presentations by Jennifer O’Neal (formerly head archivist of National Museum of American Indian and Günter Waibel (director of the Smithsonian Digitization Program). O'Neal enumerated on issues involved in the digitization and circulation of the NMAI's rich holdings. She addressed the complications that emerged when working to integrate diverse materials in George Gustav Heye's founding collection as part of making them more accessible, alongside the need to navigate their messy trajectories and legacies in relation to the expectations of indigenous communities. Waibel chronicled a collaboration between the Smithsonian Institution and the Tlingit community of southeast Alaska through new 3-D digital technologies. Describing the imaging and 3-D rendering of Tlingit sacred objects, he charted out new ways that museums can become repositories for digital renderings, which can then be reactivated as needed by tribes. 
2. Returned and received focused on how digital materials are received when multiple stakeholders are involved. Aaron Glass (Bard College), Jane Anderson (University of Massachusetts and New York University), and Surajit Sarkar (Ambedkar University) each referred to their respective projects to probe the interaction between and within indigenous communities, nationstates, collecting institutions, and local and regional communities as they relate to the return and reception of digital materials. Each of these stakeholders interact with and have specific claims to the preservation and circulation of such cultural materials and the attendant knowledge embedded within them, and this panel of the workshop addressed the intended and unintended consequences of returning materials.

Glass elaborated on his work to connect Northwest Coast collections to communities. Specifically, he reflected on the collaborations that informed his exhibit Objects of Exchange: Social and Material Transformation on the Late Nineteenth-Century Northwest Coast at the Bard Graduate Center (Glass 2011) (http://www.bgc.bard.edu/gallery/gallery-at-bgc/past-exhibitions/focusgallery-2.html), and his current project to reassemble and connect the various materials that informed Boas's 1897 monograph The Social Organization and the Secret Societies of the Kwakiutl Indians, which are now dispersed between different institutions, thus reanimating the various collaborations elided by Boas and the medium of a book (http://digitalreturn.wsu.edu/ presentation/the-distributed-text-a-critical-digital-edition-of-franz-boass-1897-monograph/). For her part, Anderson presented aspects of her collaboration with Kim Christen. Doing so, she charted out the conceptual and practical difficulties that indigenous peoples and communities have with current intellectual property law. The presentation elaborated on their collaboration to create and distribute an innovate network of licenses and labels. These are delivered through an accessible and informative digital platform designed to address the complex intellectual property needs of indigenous peoples, communities, and collectives wishing to manage, maintain, and preserve their digital cultural heritage. The presentation raised important points in relation to how Intellectual Property regimes can be used to help protect indigenous communities in the ongoing struggle for legal, political, and social recognition within the digital domain. Broadening the geographic scope of the workshop, Sarkar gave a compelling account of six years of performances in the Catapult Arts Caravan in northeast and central India. A unique opportunity for community members to comment in public on visual and audio explorations of heritage, the Catapult Arts Caravan invites community commentaries to become part of the public spectacle. Sarkar outlined how these contexts provide critical outlets for public discourse, criticism, and reconciliation within the community. His contribution pointed to important aspects of digital return in the Global South, where differently configured indigenous and political realities affect the circulation of objects and ideas.

3. Access and accountability dealt with the forms of access to and relationships with digital and material objects that occur during archival processes. Aron Crowell (Smithsonian), Sue Rowley (University of British Columbia), and Robert Leopold (Smithsonian) discussed the practical matters that arise during large-scale digitization projects with indigenous communities as well as the ways in which digital technologies can bridge some circulation divides that emerge during this process. Each looked at both macro and micro levels to explore how the digital return of materials could take into account the sensibilities and cultural needs of indigenous communities while also working within and through large institutions. The presenters also described how both sides were altered through the resulting collaborations.

Crowell reflected on a decade-long series of collaborations with communities in the Alaska region that contributed to the Sharing Knowledge Project (http://alaska.si.edu/) and the linked exhibit Living Our Cultures, Sharing our Heritage: The First Peoples of Alaska (Crowell et al. 
2010). Crowell demonstrated the effectiveness of bringing communities into conversations with collections, and addressed the challenges involved in recording, transcribing, and then presenting such knowledge to local and global audiences. Rowley gave an account of the last five years of creating and maintaining the Reciprocal Research Network (RRN). Involving nineteen institutions to date, the RRN is a unique and compelling model of intra- and interuniversity and museum collaboration with First Nations communities of Canada and, now, with other indigenous communities. Emphasizing the technical support needed across institutions, Rowley candidly detailed the long-term goals of network integration that are necessary to support larger projects. Rowley underscored an ongoing issue found throughout the workshop: digital collaborations only succeed when they are built on solid, ongoing social relations. In other words, the digital does not replace the social, but can rather help to reinforce and enable capacities that were otherwise not obtainable. Drawing on his former experience as director of the Smithsonian's National Anthropological Archive, Leopold examined the impact and complications of the return of digitized Cherokee manuscripts collected by James Mooney for the Cherokee. Taking as his starting point the gap between archival intentions and the needs of communities, Leopold examined how the dynamics of collecting play out in unusual and unexpected ways when materials are returned. Leopold provided a candid account of the different expectations and realities of such collaborations.

Following this panel, Jake Homiak, director of the Collections and Archives Program for NMNH's Department of Anthropology, reflected on the responsibilities of caring for NMNH's vast and varied collections in multiple media. He highlighted projects that are working to capitalize on the collections to engage communities more widely in the mutual production of knowledge.

4. Circulation and transformations looked broadly at the transformation of knowledge as a result of the circulation between communities and institutions. Lise Dobrin (University of Virginia), Gary Holton (University of Alaska Fairbanks), Haidy Geismar (New York University), and Rosemary Coombe (York University) discussed how endangered languages, cultural materials, intellectual property, and ephemera intermingle in divergent ways through the process of return. Although transformation can happen with any type of engagement, these presentations examined the particulars of return practices that presuppose complex political, social, historical, and legal situations involving the return of cultural and linguistic materials. Through their concrete case studies, these presentations addressed the process by which research findings at once resonate with local interests but may also become politically contested.

Both Dobrin and Holton reflected on techniques and opportunities in digital language documentation projects in their respective work in Papua New Guinea and Alaska. Each examined how generational shifts have transformed community attention to language. In each case, these shifts have reawakened community interest in documentary materials and the relationships drawn on and created by the respective projects. Through their reflections on their experiences, they reminded us how such collaborative work is processual, and how the continued access and transformative nature of the work is extended by the digital in various ways. Geismar provoked participants to think about how the digital is the new analogue, by which she means the horizon by which all media is understood and against which it is measured. Drawing on the notion of remediation and translation, Geismar reminded us of what it is that the digital does and does not do, and how it is inextricably connected to earlier media forms. Pulling together many of the themes discussed throughout the two days, Coombe moved from international indigenous movements to the need for larger sets of policies that could unite the work of indigenous communities while also leaving open the possibility of multipronged solutions, including a fundamental rethinking of Intellectual Property Rights in relation to digital heritage. 
Collectively, these presentations, which will be brought together in a special issue for Museum Anthropology Review, contribute a new set of theoretical insights into the processes and practices of knowledge creation and cultural and linguistic revitalization in relation to digital materials. By emphasizing the practices that emerge from digital return, the workshop helped to document the many, varied ways in which digital repatriation works (or does not), while also theorizing the terrain of repatriation by documenting the day-to-day uses that grow out of its implementation. Rather than merely asking if such materials should be repatriated, these presentations focused on materials that have already been digitally returned in an attempt to lay bare the types of cultural, linguistic, and social work these objects can engage in after they are returned. If digitally returned materials have unexpected uses and create new knowledge, how do we understand the role of giving back and receiving in relation to material culture? How can we reconceptualize the ethical questions of return when digital surrogates rather than the objects themselves are at stake? The workshop offered a way in to these questions by providing specific details and historic analysis of long-term projects.

By emphasizing the applied nature of digital return, the workshop's presentations highlighted the processes of labor and partnership that are part of the digital. In that way, they undo the mystification of much digital analysis and point to the types of knowledge circulation that form a tableau of interaction. Rather than fall back on the metaphors of the superhighway, or Web 2.0 notions of user-generated content and more recent calls for a focus on 'big data', the workshop helped emphasize a digital terrain that is enmeshed with the everyday practical and oftentimes messy and contradictory fields of relation, respect, and reciprocity, which cannot be reduced to a singular metaphor. As we collectively continue to engage with types of return, we can open up the possibilities for knowledge creation by the act of entering into lasting relationships. Digital return is structured by both the digital, which allows for multiplicity, and the act of return, which builds off ethical systems of relationships.

JOSHUA A. BELL is curator of globalization and director of the Recovering Voices Initiative at the Smithsonian Institution's National Museum of Natural History. Combining ethnographic fieldwork with research in museums and archives, Dr. Bell's work examines the shifting local and global network of relationships between persons, artifacts, and the environment. While the bulk of his research has been carried out in collaboration with communities in the Purari Delta of Papua New Guinea, with Joel Kuipers at George Washington University, and a team of researchers, he is conducting a new project that examines the use, meanings, and repair of cell phones in the Washington DC metropolitan region.

MARK TURIN is a linguist and anthropologist. Before joining the South Asian Studies Council at Yale, Mark was a research associate at the Museum of Archaeology and Anthropology at the University of Cambridge. Now colocated at Cambridge and Yale, Mark directs both the World Oral Literature Project and the Digital Himalaya Project. He is the author or coauthor of four books, the editor of seven volumes, and the editor of a new series with the Cambridge-based Open Book Publishers. He is the program director of Yale's new Himalaya Initiative.

KIMBERLY CHRISTEN is an associate professor in the Department of Critical Culture, Gender and Race Studies and the director of digital projects at the Plateau Center for American Indian Studies at Washington State University. Her research focuses on the intersection of digital technologies, archival practices, cultural heritage movements, and intellectual prop- 
erty rights within indigenous communities and the global commons. Dr. Christen is currently directing the Plateau Peoples' Web Portal (http://plateauportal.wsulibs.wsu.edu/), an online collaboratively curated site for Plateau cultural materials, and Mukurtu CMS (www .mukurtu.org<http://www.mukurtu.org/), a free, open-source digital archive and content management tool designed to meet the needs of indigenous communities as they manage and share their digital cultural heritage.

\section{NOTES}

1. The workshop resulted in two key outputs: a website (http://digitalreturn.wsu.edu) that acts as an ongoing research network hub for cataloguing digital return projects globally and linking communities to resources, and a special issue of Museum Anthropology Review containing articles from a majority of the invited participants (this will be published June 2013). This workshop report is based in part on the Introduction to that special issue written by the three conveners of the workshop: Joshua A. Bell, Kimberly Christen, and Mark Turin.

2. Flickr is a photo-sharing site that allows users to upload, annotate, comment on, and provide access to their personal photos. Omeka is an exhibition platform tool that allows individuals or institutions to use template-based sets to produce their own online exhibitions.

3. A farmer, an artist, and a cultural visionary, Enote received the 2010 Council of Museum Anthropology's inaugural Michael Ames Prize for Innovative Museum Anthropology in recognition of his pioneering work over many years that has included a number of projects with digital components (e.g., Srinivasan et al. 2010). The full keynote can be found at http://digitalreturn.wsu.edu/workshop/.

\section{REFERENCES}

Boast, Robin, Michael Bravo, and Ramesh Srinivasan. 2007. "Return to Babel: Emergent Diversity, Digital Resources, and Local Knowledge." The Information Society, 23 (5): 395-403.

Bell, Joshua A. 2008. "Promiscuous Things: Perspectives on Cultural Property Through Photographs in the Purari Delta of Papua New Guinea." International Journal of Cultural Property 15 (2): 123-139.

Bell, Joshua A. 2010 "Out of the Mouths of Crocodiles: Eliciting Histories with Photographs and String Figures." History and Anthropology 21 (4): 351-373.

Cameron, Fiona, and Sarah Kenderdine. 2007. Theorizing Digital Cultural Heritage: A Critical Discourse. Cambridge: MIT Press.

Christen, Kim. 2005 "Gone Digital: Aboriginal Remix in the Cultural Commons." International Journal of Cultural Property 12: 315-345.

Christen, Kim. 2009. Aboriginal Business: Alliances in a Remote Australian Town. Santa Fe, NM: School of Advanced Research Press.

Christen, Kim. 2011. “Opening Archives: Respectful Repatriation.” American Archivist 74: 185-210.

Coombe, Rosemary J. 2009 "The Expanding Purview of Cultural Properties and their Politics." Annual Review of Law and Social Sciences 5: 393-412.

Crowell, Aron A., Worl, Rosita, Ongtooguk, Paul C., and Dawn D. Biddison 2010. Living Our Cultures, Sharing Our Heritage: The First People's of Alaska. Washington DC: Smithsonian.

Geismar, Haidy, and W. Mohns. 2011. "Database Relations: Rethinking the Database in the Vanuatu Cultural Centre and National Museum." In "The Aesthetics of Nations: Anthropological and Historical Approaches," ed. C. Pinney and N. Mookherjee. Special issue, Journal of the Royal Anthropological Institute NS: S133-S155.

Ginsburg, Faye, Lila Abu-Lughod, and Brian Larkin, eds. 2002. Media Worlds: Media Worlds: Anthropology on New Terrain. Berkeley: University of California Press. 
Karp, Ivan, Kratz, Corinne A., Szwaja, Lynn and Ybarra-Frausto, Tomas ds. 2006. Museum Frictions: Public Cultures/Global Transformations. Durham, NC: Duke University Press.

Peers, Laura L., and Alison K. Brown, eds. 2003. Museums and Source Communities: A Routledge Reader. London: Routledge.

Phillips, Ruth B. 2012. Museum Pieces: Toward the Indigenization of Canadian Museums. Montreal: McGill-Queen's University Press.

Salmond, Amiria. 2012. "Digital Subjects, Cultural Objects: Special Issue Introduction." Journal of Material Culture 17 (3): 211-228.

Srinivasan, Ramesh, Boast, Robin, Becvar, Katharine and Enote, Jim 2010. "Diverse Knowledges and Contact Zones Within the Digital Museum.” Science, Technology, \& Human Values 34 (5): 735-768.

Turin, Mark. 2007. Linguistic Diversity and the Preservation of Endangered Languages: A Case Study from Nepal. Kathmandu: ICIMOD.

Turin, Mark. 2011. "Born Archival: The Ebb and Flow of Digital Documents from the Field." History and Anthropology 22 (4): 445-460. 